\title{
Geociências
}

\section{Reavaliação genética do modelo do Vulcão de Nova Iguaçu, RJ: origem eruptiva ou intrusão subvulcânica?}

\section{(Genetic reconsideration of the Nova Iguaçu Volcano model, State of Rio de Janeiro, Brazil: eruptive origin or subvolcanic intrusion?)}

\author{
Akihisa Motoki \\ Departamento de Mineralogia e Petrologia Ígnea, \\ Universidade do Estado do Rio de Janeiro \\ E-mail: rochasornamentais@yahoo.com.br \\ Rodrigo Soares \\ Departamento de Mineralogia e Petrologia Ígnea, \\ Universidade do Estado do Rio de Janeiro \\ E-mail: roddrigoss@yahoo.com.br \\ Ana Maria Netto \\ Departamento de Geologia Regional e Geotectônica, \\ Universidade do Estado do Rio de Janeiro \\ E-mail:nettoana@superig.com.br
}

\section{Resumo}

O presente trabalho reexamina as estruturas geológicas que foram consideradas como de origem eruptiva do Complexo Alcalino de Mendanha, no Estado do Rio de Janeiro. O vale interpretado como cratera não é constituído por aglomerado piroclástico, mas por traquito maciço. $\mathrm{O}$ depósito aluvionar presente no referido vale é composto de materiais regolíticos de espessura de poucos metros. Não foi encontrado o tálus composto de grandes blocos sugestivo de colapso da cratera. Não ocorre a saliência morfológica correspondente ao cone vulcânico. Os afloramentos em torno da suposta cratera não apresentam a estratificação vulcânica. Desta forma, considera-se que esse vale não corresponde à cratera vulcânica, mas a uma morfologia originada de erosão. O traquito mais abundante é intrudido pelo álcali sienito e, portanto, não pode ser derrame de lava que cobre o sienito. O traquito ocorre até o topo do maciço, $600 \mathrm{~m}$ acima da suposta cratera. A disjunção colunar é originada de diques e a estrutura parecida à crosta-de-pão é atribuída a intemperismo. As observações anteriores indicam que esse traquito não é constituinte de derrames de lava, mas de corpos subvulcânicos. Os autores concluem que as rochas vulcânicas em questão não são constituintes de edifício vulcânico, mas de preenchimento de condutos e fissuras subvulcânicos, e a hipótese do Vulcão de Nova Iguaçu é inviável.

Palavras-chave: Nova Iguaçu, vulcão, corpo subvulcânico, cratera, cone, lava.

\author{
Susanna Eleonora Sichel \\ LAGEMAR, Universidade Federal Fluminense \\ E-mail:susanna@igeo.uff.br
}

José Ribeiro Aires

ABAST, Petrobras.

E-mail: aires@petrobras.com.br

Marcela Lobato

Departamento de Mineralogia e Petrologia Ígnea, Universidade do Estado do Rio de Janeiro

E-mail:marcela_lob@hotmail.com

\begin{abstract}
This paper re-examines the geologic structures that were considered to be of eruptive origin of the Mendanha Alkaline Complex, State of Rio de Janeiro, Brazil. The valley interpreted to be a crater is not underlain by pyroclastic agglomerate, but by massive trachyte. The alluvial deposit on this valley is a few meters thick and composed of regolitic materials. The talus deposit of large boulders suggestive of crater wall collapse is not observed. No morphologic elevation indicative of volcanic cone is found. The outcrops around the supposed crater show no volcanic stratification. The valley is not considered to be a volcanic crater but a landform resulted from erosion. The most abundant trachyte of this area is cut by the alkali syenite, and therefore, cannot be the lava flow that covers the syenite. The trachyte takes place up to the top of the massif, $600 \mathrm{~m}$ above the supposed crater. The columnar joints are originated from dikes, and the bread crust-like structure is attributed to weathering. These observations indicate that the trachyte is not constituent of lava flows, but of subvolcanic bodies. The authors conclude that the volcanic rocks in question are not constituent of volcanic edifice, but of subvolcanic vent-filling tuff breccia, and the hypothesis of the Nova Iguaçu Volcano is implausible.
\end{abstract}

Keywords: Nova Iguaçu, volcano, subvolcanic body, crater, cone, lava. 


\section{Introdução}

Na borda nordeste do maciço Mendanha, Município de Nova Iguaçu, RJ, ocorrem rochas vulcânicas do final do Cretáceo ao início do Terciário (Figura 1). Essas rochas foram interpretadas como constituintes de um vulcão extinto com a cratera e o cone extraordinariamente bem preservados, denominado "Vulcão de Nova Iguaçu” (Klein \& Vieira, 1980; Klein et al., 1984; Klein, 1993; Vieira \& Klein, 2004). O DRM (Departamento de Recursos Minerais do Estado do Rio de Janeiro), junto com os colaboradores, instalou placas descritivas de pontos de interesse geológico para o suposto vulcão no Parque Municipal de Nova Iguaçu, como uma parte do Projeto Caminhos Geológicos (Ghizi et al., 2004).

Vieira (2005) comentou que esse é o único vulcão intacto no país e a nítida morfologia de cratera estaria sendo destruída pela mineração de pedreira. Na mesma época, foi entregue ao Ministério Público uma denúncia de mesmo conteúdo, requerendo interdição da pedreira Vigné. O processo judicial motivou o projeto TAC (instrumento dos termos de ajustamento de conduta aplicados a empreendimentos minerais no Estado do Rio de Janeiro), que foi realizado pelo DRM e colaboradores universitários sob apoio financeiro da Pedreira Vigné. Os resultados dos estudos geológicos foram apresentados na forma de um relatório final (Valente et al., 2005).

Os trabalhos idealizadores da hipótese Vulcão de Nova Iguaçu consideraram a existência de cratera, edifício vulcânico, derrames de lava e fluxos piroclásticos como justificativas fundamentais. Entretanto pesquisas recentes colocam em dúvida essa hipótese, propondo que a estrutura geológica em questão não corresponde a um vulcão, mas aos condutos e fissuras subvulcânicos de quilômetros de profundidade (Motoki \& Sichel, 2006; Motoki et al., 2006; 2007a; b).

O presente artigo reexamina a geologia das áreas apontadas como a cratera vulcânica e o cone vulcânico e as feições interpretadas como de derrames de lava. Com base nisso, os autores reavaliam a hipótese do Vulcão de Nova Iguaçu, apresentando um modelo geológico alternativo.

\section{Geologia e morfologia da suposta cratera}

Uma cratera vulcânica é definida como sendo a morfologia negativa circular formada por erupção explosiva (e.g. MacDonald, 1972). A explosão forma brecha com grandes clastos angulosos, denominada brecha de explosão (explosion breccia), que se espalham ao redor da cratera. Por outro lado, dentro do conduto vulcânico, ocorre rocha piroclástica com clastos arredondados e semi-arredondados, denominada brecha de conduto (vent breccia).

A hipótese da cratera em Nova Iguaçu foi noticiada pela Rede Globo (Vieira, 2004) e pela homepage do DRM (Medeiros \& Ragatky, 2004), apontando o vale em forma de ferradura aberta ao norte localizado cerca de $2 \mathrm{~km}$ ao sul da zona urbana (Loc. 1, Figura 1). Valente et al. (2005) determinaram o tamanho dessa morfologia como sendo de $800 \mathrm{~m}$ de dimensão norte-sul, 700 m de lesteoeste e 200 m de profundidade (Figura 2A).

Vieira e Klein (2004) apresentaram um perfil de direção norte-sul da cratera com a parede interna subvertical (Figura 3A). Entretanto, com base no mapa topográfico na escala 1:10.000 do CEDE, Centro de Informação e Dados do Rio de Janeiro, verifica-se um perfil diferente (Figura 3B, C). A parede lateral do vale tem ângulo suave de 15 a $20^{\circ}$, sendo coerente com taludes formados por erosão. Portanto a morfologia tridimensional desse vale é incompatível com o modelo de cratera intacta.

Klein e Vieira (1980) interpretaram a rocha constituinte da cratera como sendo aglomerado vulcânico. A cratera corresponderia ao centro da área semicircular de distribuição do aglomerado e da brecha (Figura 1A). Entretanto Valente et al. (2005) revelaram que a rocha desse vale não é brecha, mas traquito maciço
(Loc. 1, Figura 2B). Portanto interpretaram que o vale não corresponde à cratera, mas à janela geológica formada por erosão e as rochas vulcânicas são constituintes de um vulcão erodido, sem preservação da morfologia original.

\section{Depósito aluvionar na suposta cratera}

Crateras e caldeiras vulcânicas freqüentemente formam lagos, que, após o rompimento, geram depósitos lacustres. Os mapas geológicos de Klein e Vieira (1980) e Valente et al. (2005) apresentaram depósito aluvionar no vale da suposta cratera (Figura 1A). As observações de campo pelos autores revelaram que esse depósito é composto de materiais lateríticos, sendo indistinguível de depósitos de origem regolítica. Além disso, sua espessura é pequena, da ordem de apenas poucos metros. Dessa forma, considera-se que o depósito não é sedimento lacustre.

Se o vale fosse remanescente da cratera, deveria existir um grande volume de tálus composto de blocos angulosos de 1 a 10 m originados de desmoronamentos da parede interna (Figura 4A). Por outro lado, quando o vale é originado de erosão, o tálus presente é pouco expressivo (Figura 4B). Os trabalhos de campo revelaram que o depósito de tálus ocorre apenas em localidades isoladas e é composto de blocos de tamanho inferior a $30 \mathrm{~cm}$. Portanto, não se encontram indícios de grande desmoronamento.

\section{Geologia do suposto cone vulcânico}

Um edifício vulcânico é definido como sendo a elevação morfológica formada diretamente por erupções e conseqüentes acúmulos de materiais eruptivos na superfície da Terra (e.g. MacDonald, 1972; Motoki \& Sichel, 2006). O edifício vulcânico de forma cônica é denominado “cone vulcânico”. 


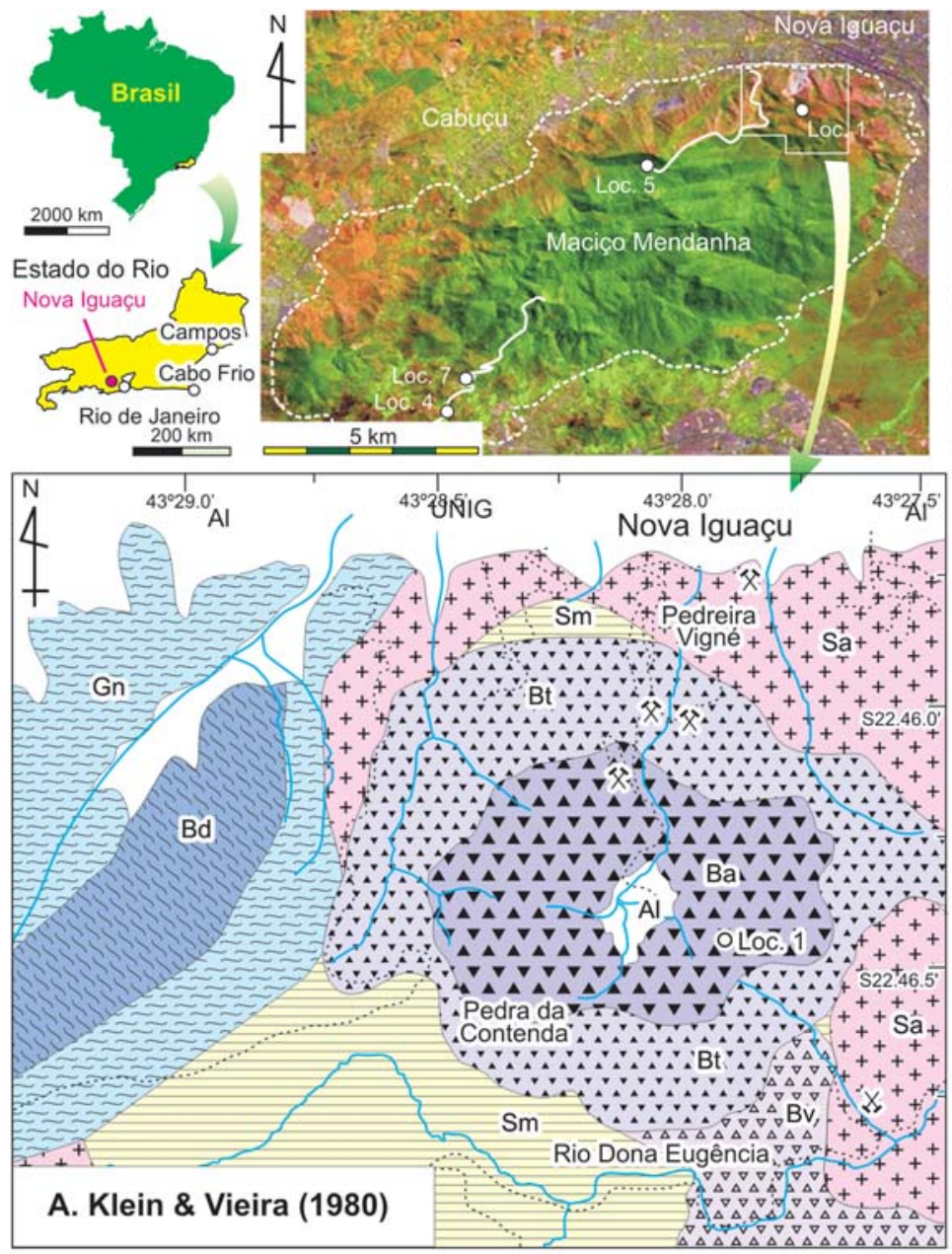

Loc. 1 S22 $46.44^{\prime \prime}$ W43⒉ $271^{\prime} \quad \mathrm{H} 286 \mathrm{~m}$

Loc. 2 S22 $26.80^{\circ} \quad W^{\circ} 43^{\circ} 28.11^{\prime}$ H200m

Loc. 3. S22 $45.76^{\prime} \mathrm{W}^{\prime} 43^{\circ} 28.62^{\prime} \mathrm{H} 133 \mathrm{~m}$

Loc. 4. S22 ${ }^{\circ} 50.12^{\prime} \quad \mathrm{W}^{\prime} 3^{\circ} 32.53^{\prime} \quad \mathrm{H} 175 \mathrm{~m}$

Loc. 5. S $22^{\circ} 47.07^{\prime} \quad \mathrm{W}^{\prime} 43^{\circ} 30.05^{\prime} \mathrm{H} 885 \mathrm{~m}$

Loc. 6. S22 $45.89^{\prime} \quad W^{\prime} 43^{\circ} 28.54^{\prime} \quad \mathrm{H} 180 \mathrm{~m}$

Loc. 7. S22 ${ }^{\circ} 50.05^{\prime} \quad W 43^{\circ} 32.51^{\prime} \mathrm{H} 230 \mathrm{~m}$

Loc. 8. S22 $46.08^{\prime} \quad W^{\prime} 43^{\circ} 28.13^{\prime} \quad \mathrm{H} 220 \mathrm{~m}$

Loc. 9. S22 $45.80^{\prime}$ W $43^{\circ} 28.16^{\prime} \quad \mathrm{H} 71 \mathrm{~m}$

Loc. 10. S22 $46.10^{\prime} \quad W^{\prime} 43^{\circ} 27.90^{\prime} \quad \mathrm{H} 85 \mathrm{~m}$

Loc. 11. S22 $46.03^{\prime} \quad \mathrm{W}^{\prime} 3^{\circ} 28.00^{\prime} \mathrm{H} 195 \mathrm{~m}$

Loc. 12. S22 $46.38^{\prime} \quad W^{\prime} 43^{\circ} 27.94^{\prime}$ H305 m

Loc. 13. S22 ${ }^{\circ} 46.40^{\prime} \quad W 43^{\circ} 27.71^{\prime} \mathrm{H} 392 \mathrm{~m}$

Loc. 14. S $22^{\circ} 46.70^{\prime} \quad W 43^{\circ} 27.66^{\prime} \mathrm{H} 240 \mathrm{~m}$

Loc. 15. S22 $46.43^{\prime} \quad$ W43 $27.81^{\prime}$ H 370 m

Loc. 16. S22 $46.64^{\prime}$ W4 $43^{\circ} 28.09$ H420 m

Loc. 17. S22 ${ }^{\circ} 46.95^{\prime} \quad \mathrm{W}^{\prime} 43^{\circ} 27.95^{\prime} \mathrm{H} 195 \mathrm{~m}$

Loc. 18. $\mathrm{S} 22^{\circ} 46.44^{\prime} \quad \mathrm{W}^{\prime} 43^{\circ} 28.26^{\prime} \mathrm{H} 410 \mathrm{~m}$

Legenda para Klein \& Vieira (1980)

Al Aluvião

Âầ Aglomerado vulcânico

$\therefore$ Bt?.-A Brecha tufitica

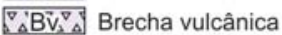

Bd. Brecha tectônica deformada

$\mathrm{Sm} \exists$ Microsienito porfirítico

${ }_{+}^{+} \mathrm{Sa}^{+}+$Sienito

$\square$ Gnaisse

\section{Ordem de intrusão dos corpos geológicos de Nova Iguaçu}
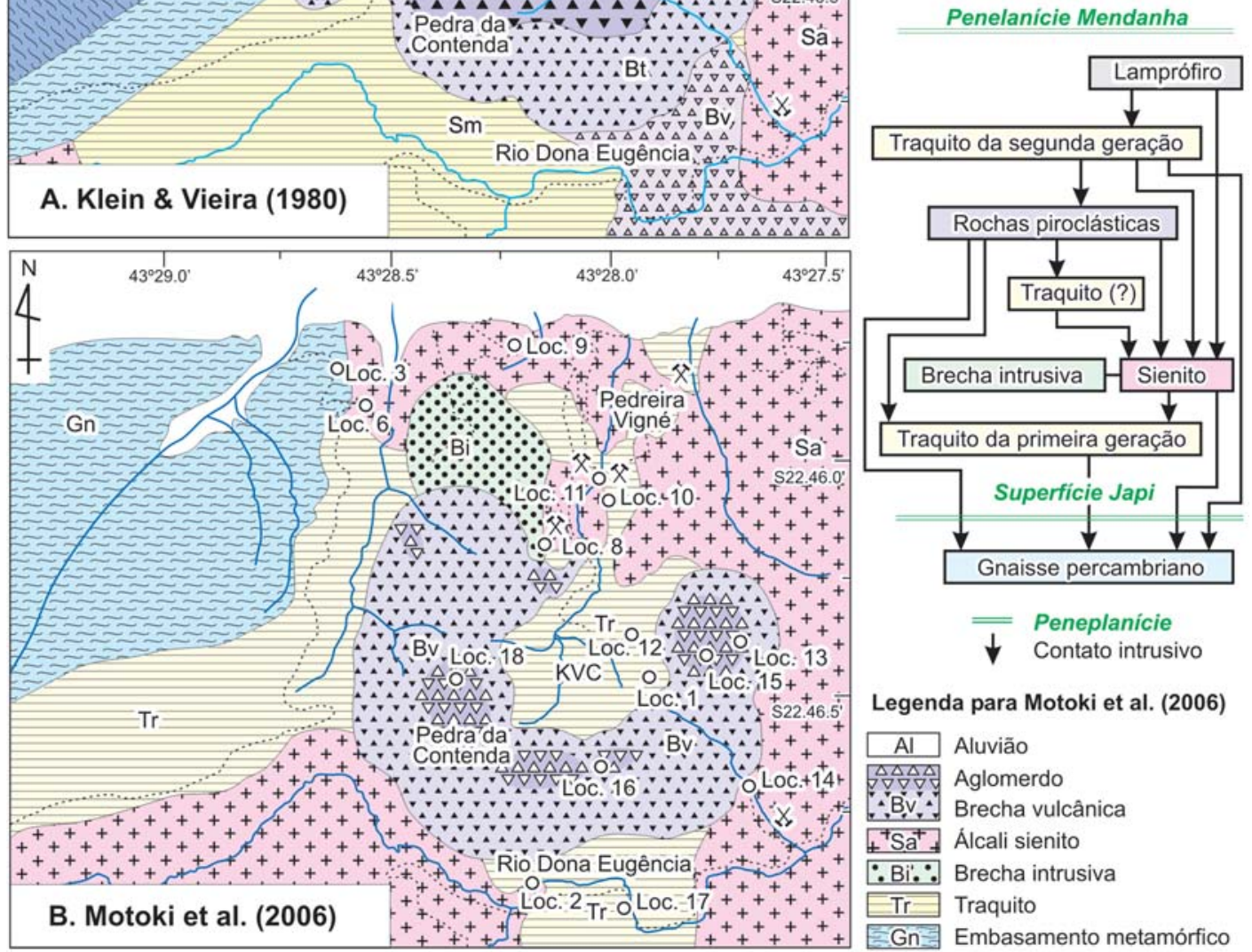

Legenda para Motoki et al. (2006)

\begin{tabular}{|c|c|}
\hline $\mathrm{Al}$ & Aluvião \\
\hline$\Delta \Delta \Delta \Delta$ & Aglomerdo \\
\hline$\therefore B \vee \div$ & Brecha vulcânica \\
\hline${ }^{+} \mathrm{Sa}^{+}=$ & Álcali sienito \\
\hline$\because \mathrm{Bi}^{\prime}:$. & Brecha intrusiva \\
\hline $\mathrm{Tr}=$ & Traquito \\
\hline $\mathrm{Gn}=$ & Embasamento metamórfico \\
\hline
\end{tabular}

Figura 1 - Comparação dos mapas geológicos da área de rochas vulcânicas de Nova Iguaçu segundo: A) Klein e Vieira (1980); B) mapa dos autores; C) relações intrusivas observadas pelos autores. A imagem de satélite é originada da EMBRAPA. As localidades citadas no texto situadas fora do mapa B são expressas na imagem de satélite. 
Vieira e Klein (2004) apresentaram uma ilustração do que eles denominaram cone vulcânico em Nova Iguaçu, de 1.7 km de diâmetro na base, 250 m de altura relativa e $27^{\circ}$ de ângulo do flanco (Figura 3A). Sendo assim, o edifício vulcânico destacar-se-ia proeminentemente no flanco nordeste do maciço Mendanha, sendo reconhecido facilmente da cidade de Nova Iguaçu. O que, entretanto, não ocorre.

O tamanho, a forma e o ângulo do flanco sugerem que o corpo em questão pode ser um cone piroclástico (cinder cone), formado por erupção monogênica de magma basáltico. Entretanto os trabalhos a favor da hipótese do vulcão propuseram erupções poligênicas explosivas de magma félsico (Klein \& Vieira, 1980; Klein et al., 1984; Vieira \& Klein, 2004; Silveira et al., 2005; Valente et al., 2005). Tal tipo de erupção não é compatível com a formação de um cinder cone.

Perfis de cones vulcânicos mostram estratificações suborizontais de grande continuidade. Vulcões andesíticos e traquíticos apresentam estratificação constituída por spatter soldada. A spatter corresponde às as gotas semiconsolidadas de magma ejetadas a partir da cratera. Durante a acumulação na superfície da Terra, spatters são achatadas por deformação plástica e aglutinadas pelo próprio peso, sendo chamadas de spatter soldado (welded spatter). A espessura individual das camadas de spatter soldado é de 1 a 3 m (Figura 5). Entretanto os afloramentos presentes no suposto cone vulcânico não apresentam essa estratificação, mas expõem traquito maciço (Figura 2B).

Vieira e Klein (2004) indicaram que a base do edifício vulcânico está exposta no Poço das Cobras (Loc. 2, Figura 1B), na cota de $180 \mathrm{~m}$. Entretanto a rocha piroclástica exposta nesse afloramento não é fluxo piroclástico, mas um dique intrusivo no sienito, correspondendo a uma fissura subvulcânica (Motoki et al., 2007b).
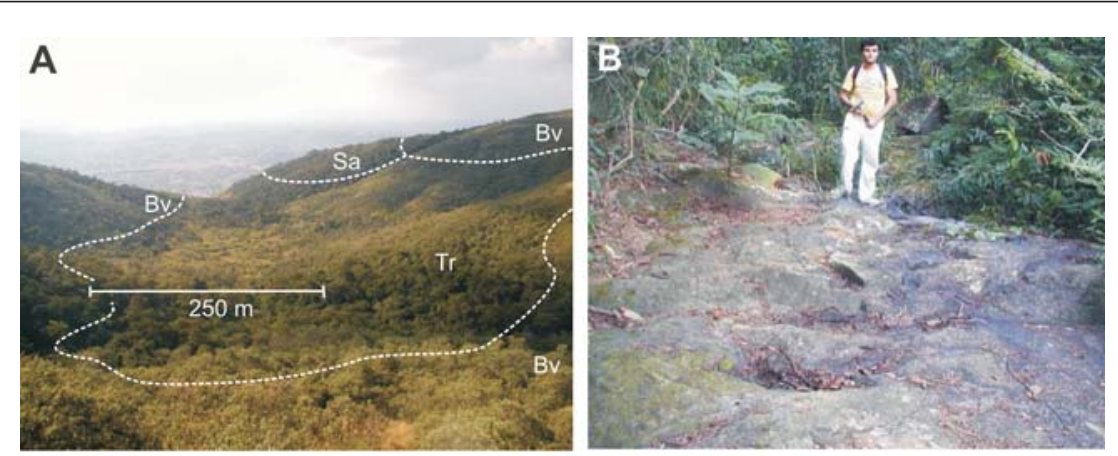

Bv: Brecha vulcânica

Sa: Álcali sienito

Tr: Traquito da primeira geração

Figura 2 - Vale da suposta cratera: A) vista geral fotografada a partir da Pedra Austral (Loc. 16, Figura 1B); B) rocha constituinte do vale em Poço dos Bois (Loc. 1), traquito porfirítico maciço da primeira geração.

Klein e Vieira (1980), Silveira et al. (2005) e Valente et al. (2005) apontaram a presença de brecha com acamamento suborizontal. Entretanto os trabalhos de campo realizados pelos autores revelaram que as camadas piroclásticas são pouco contínuas e os contatos entre elas são ambíguos, irregulares e de alto ângulo (Motoki et al., 2007a). Os contatos entre os corpos piroclásticos e a rocha encaixante sienítica também são sub-verticais (Figura 3C, D). Portanto esse acamamento é incompatível com os perfis de edifícios vulcânicos.

\section{Hipótese de derrames de lava traquítica}

Silveira et al. (2005) e Valente et al. (2005) classificaram o traquito por cores de intemperismo e quantidade de fenocristais: 1) traquito porfirítico cinza-claro (Figura 6A, C); 2) traquito porfirítico lilás (Figura 6B); 3) pórfiro traquito (Figura 6D).

O traquito porfirítico cinza-claro é o mais abundante nessa área. Tem fenocristais de feldspato alcalino de 5 a $10 \mathrm{~mm}$ em quantidade modal de $21.5 \%$. A massa fundamental é holocristalina de granulometria relativamente grossa, com micrólitos de feldspato alcalino de com- primento de $0.5 \mathrm{~mm}$ e largura de $0.1 \mathrm{~mm}$ (Figura 6B).

Os afloramentos de contato revelam que esse traquito não cobre o embasamento metamórfico, mas é intrusivo neste. Na estrada de acesso à serra do Vulcão (Loc. 3, Figura 1B) e às torres de comunicação (Loc. 4), ocorrem diques irregulares do traquito intrusivos no embasamento metamórfico (Figura 7A).

O traquito é intrudido pelo sienito. Um afloramento da serra do Vulcão (Loc. 5, Figura 1) mostra dique de álcali sienito de granulometria de 1 a $2 \mathrm{~mm}$ e com espessura aproximada de $20 \mathrm{~cm}$, intrusivo na rocha traquítica (Figura 7B). Na estrada de acesso (Loc. 6, Figura 1B), encontra-se localmente álcali sienito dentro da área de traquito. A distribuição litológica desses pontos sugere que o álcali sienito ocorre como corpos intrusivos tabulares de espessura aproximada de $10 \mathrm{~m}$. Na estrada de acesso às torres de comunicação (Loc. 7, Figura 1), observam-se corpos de nefelina sienito intrusivos no traquito. Nessa localidade, ocorrem xenólitos angulosos de traquito de tamanho métrico dentro do sienito, indicando uma intrusão por magmatic stoping.

Na Pedreira Vigné (Loc. 8, Figura 1) e no condomínio que se situa na proximidade da Universidade de Nova Igua- 
A. Vieira \& Klein (2004) cratera

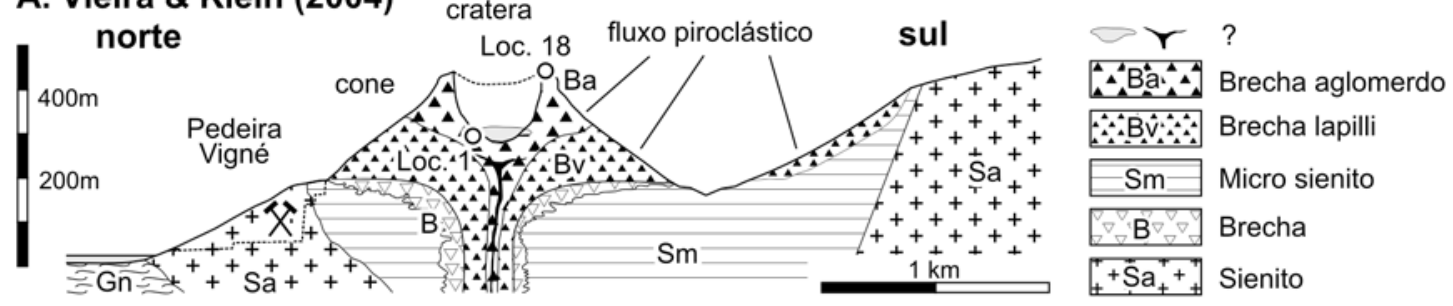

B. Valente et al. (2005), Silveira et al. (2005)

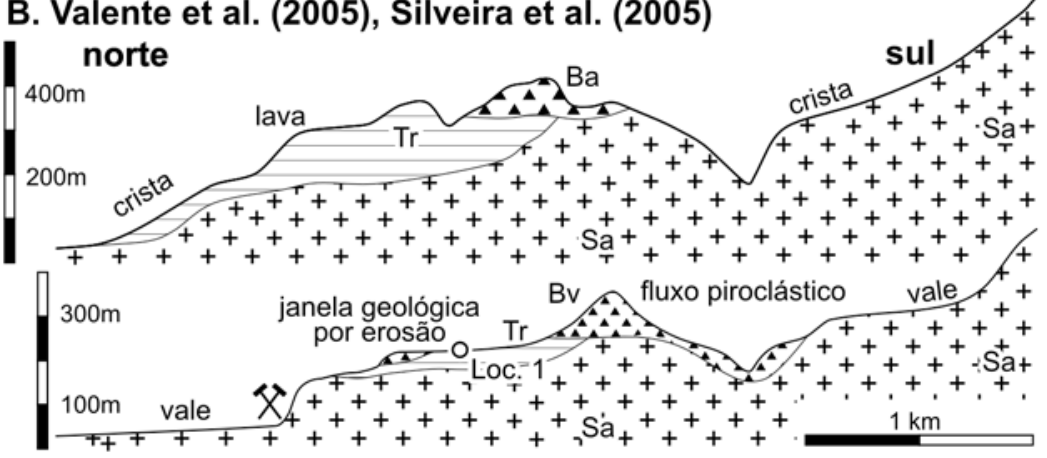

B

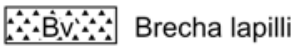

$\left[+\mathrm{Sa}^{+}{ }^{+}+\right.$Álcali sienito

$\because \mathrm{Bi}^{\prime}$. . Brecha intrusiva

$\mathrm{Tr}$ Traquito

Gñ Embasamento

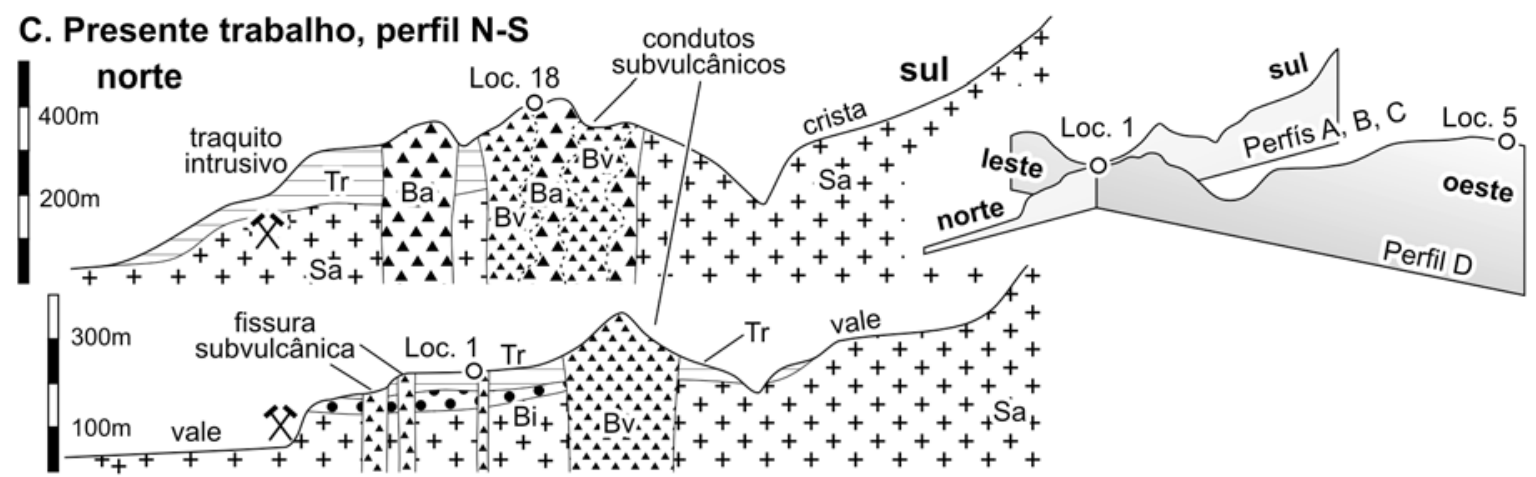

D. Presente trabalho, perfil E-W

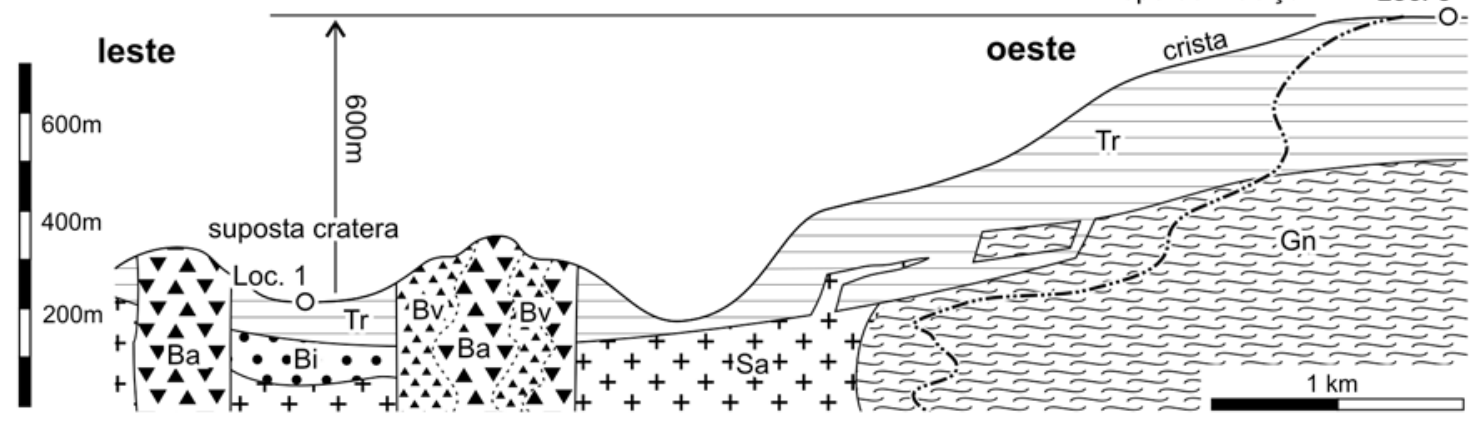

Figura 3 - Perfis geológicos do vale da suposta cratera: A) perfil norte-sul, Vieira e Klein (2004); B) norte-sul, Valente et al. (2005); C) norte-sul e D) leste-oeste, presente trabalho. Nota-se que o perfil A não está de acordo com o mapa topográfico da região. Os diagramas B e C apresentam perfis ao longo da crista e do vale. A escala vertical em A é exagerada 2,5 vezes, conforme Vieira e Klein (2004) e, para comparação, os perfis B, C e D seguem o mesmo padrão. A legenda do perfil B é válida também para C e D. 
A. Vale originado de cratera

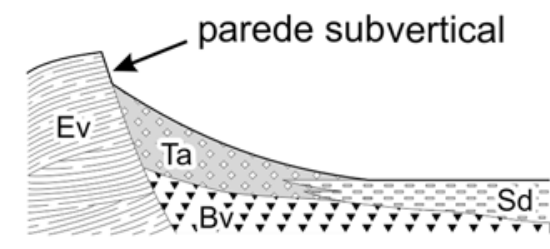

\section{B. Vale formado por erosão}

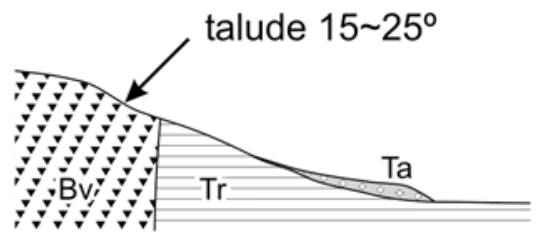

Figura 4 - Perfil geológico esquemático de vale originado de: A) cratera vulcânica; B) erosão. O perfil A é baseado nas observações de vulcões jovens (Motoki \& Sichel, 2006) e o perfil B, na observação de campo da região do Rio de Janeiro.

çu (Loc. 9, Figura 1), encontram-se xenólitos de traquito com 20 a 50 cm capturados por álcali sienito, formando brecha intrusiva de textura agmática (Figura 6A). Os xenólitos traquíticos, expostos na zona de contato entre o traquito e o álcali sienito, foram descritos por Valente et al. (2005), que os interpretaram como brecha polimítica originada de erupção vulcânica explosiva cobrindo a superfície erosiva do álcali sienito. Entretanto a matriz sienítica é incompatível com essa interpretação.

Mesmo considerando a granulometria relativamente grossa da massa fundamental, o traquito da primeira geração ainda é excessivamente fino, quando se considera o tamanho do corpo intrusivo de traquito, que deve ter-se resfriado lentamente devido ao volume muito grande de magma. $\mathrm{O}$ fenômeno similar ocorre em alguns complexos alcalinos félsicos, tais como Itaúna e Tinguá, RJ, e Poços de Caldas, MG, cuja granulometria é fina apesar de serem corpos intrusivos de 3 a $30 \mathrm{~km}$ de diâmetro. A causa desse fenômeno ainda não foi bem esclarecida, podendo ser atribuída ao teor insuficiente de fluidos no magma.

Por outro lado, o traquito porfirítico lilás e o pórfiro traquito, que têm a massa fundamental devitrificada (Figura 6D), ocorrem como diques intrusivos no sienito (Valente et al., 2005; Figura 6C) e são, por isso, classificados como de segunda geração. Esse traquito é caracterizado por massa fundamental com textura devitrificada.

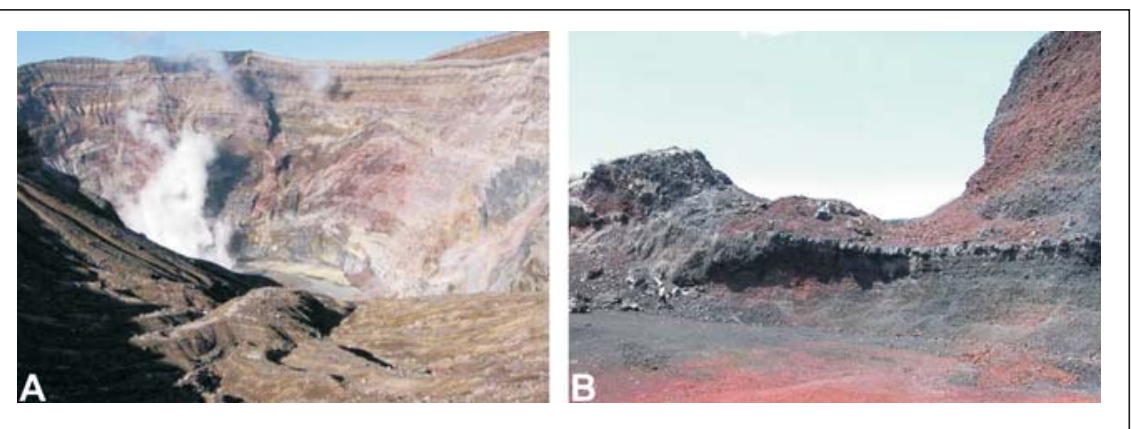

Figura 5 - Afloramentos que expõem perfil de cones vulcânicos: A) cratera de Nakadake, Vulcão Aso, Kyushu, Japão, apresentando a estratificação composta de welded spatter; B) flanco inferior de um cone piroclástico da região de Malargue, província de Mendoza, Argentina, mostrando o acamamento formado por acúmulo de escórias e spatters.

Geraldes e Netto (2004), Silveira et al. (2005) e Valente et al. (2005) propuseram que o traquito da primeira geração seria constituinte de derrames de lava. Essa hipótese é contrariada em quatro pontos: 1) idade relativa do traquito; 2) distribuição espacial do traquito; 3) idades Ar-Ar relativas das rochas ígneas; 4) nível de denudação regional.

Conforme a discussão anterior, esse traquito é intrudido pelo sienito, portanto não pode constituir derrames de lava que cobrem a superfície erosiva sienítica.

Valente et al. (2005) afirmam que esse traquito é distribuído somente no vale da suposta cratera, desde a Pedreira Vegné, na cota de 40 m (Loc. 10), até a suposta cratera, de 250 m (Loc. 1). Silveira et al. (2005) interpretaram que as lavas traquíticas se originaram da cratera e escoaram por esse vale até a proximidade da zona urbana. Observando somente o perfil norte-sul, o traquito parece estar cobrindo o sienito (Figura 3B, C). Entretanto o perfil leste-oeste (Figura 3D) demonstra que esse traquito continua até o topo do maciço (Loc. 5, Figura 1), de cota de $885 \mathrm{~m}$. Se o traquito fosse lava, os derrames deveriam ter escalado a rampa oriental do maciço desde a cratera até a serra do Vulcão, com desnível superior a 600 m. Além disso, a distribuição horizontal do corpo traquítico é muito grande, encontrando-se desde a borda nordeste do maciço Mendanha até a borda sudoeste, com extensão aproximada de 12 km (Figura 8).

As relações intrusivas observadas no campo esclarecem que o evento magmático mais antigo é o traquito da primeira geração e o mais novo é um dique de lamprófiro 2.5 m de largura, encontrado na Pedreira Vigné (Loc. 11, Figura 1C). 
Traquito da primeira geração
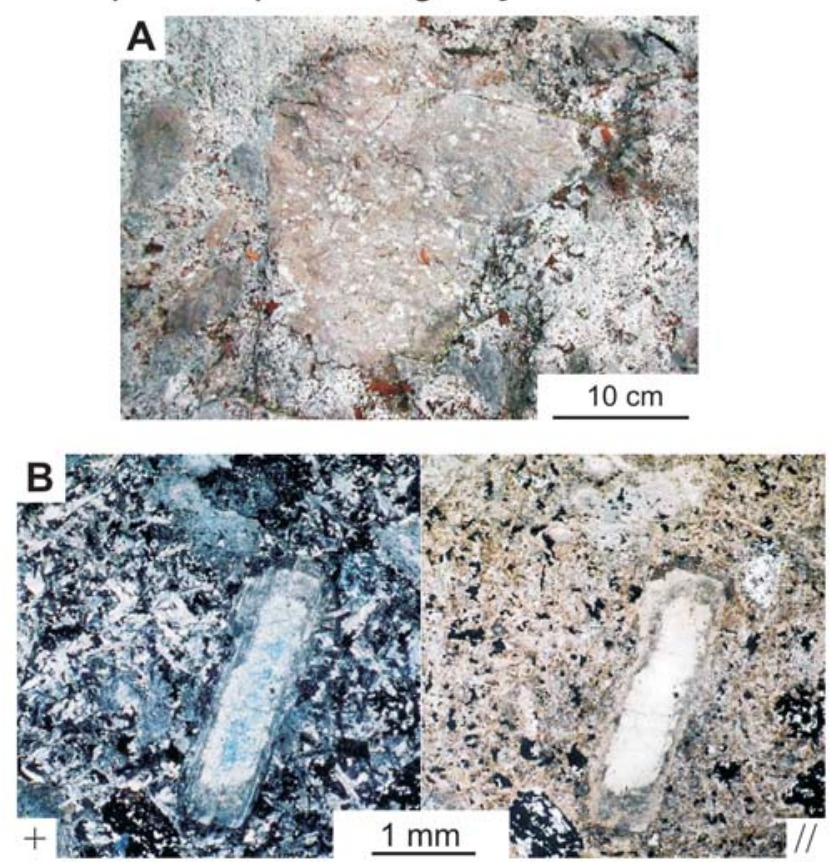

Traquito da segunda geração
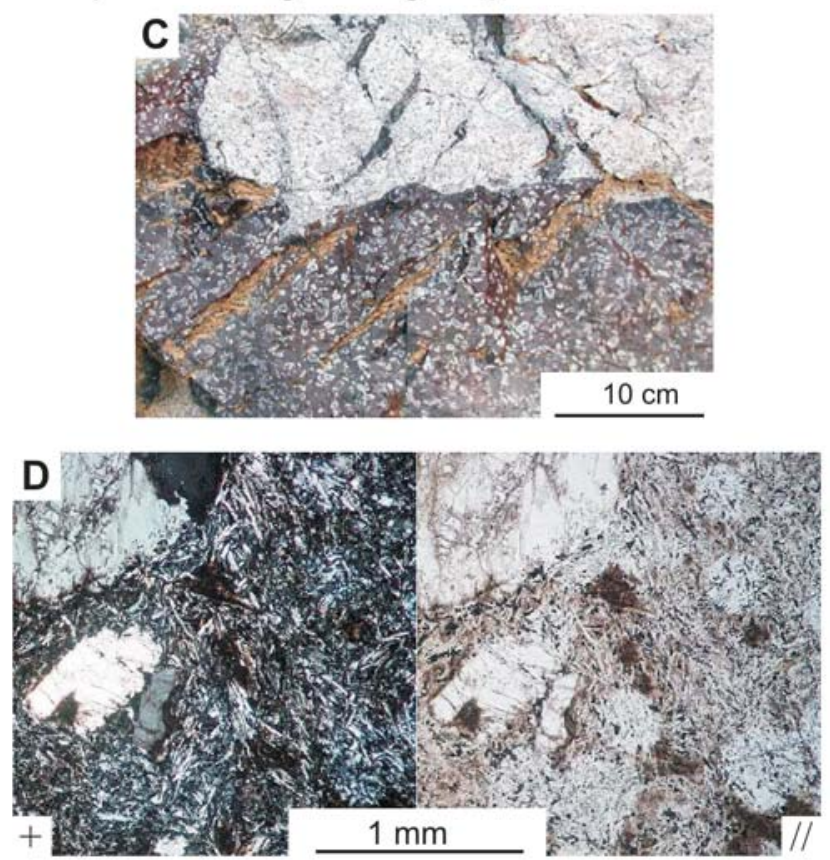

Figura 6 - Duas gerações de traquito: A) fragmento de traquito da primeira geração capturado pelo corpo plutônico de álcali sienito formando brecha intrusiva, Pedreira Vigné (Loc. 8, Figura 1B); B) fotomicrografia de traquito da primeira geração, Vale de Dona Rio Eugênia (Loc. 17); C) dique de traquito porfirítico da segunda geração, apresentando aspecto porfirítico com a cor intempérica lilás (Loc. 11); D) fotomicrografia de pórfiro traquito, da segunda geração, um clasto de brecha vulcânica na Pedra da Contenda (Loc. 18), com textura esferolítica remanescente altamente desenvolvida.

A

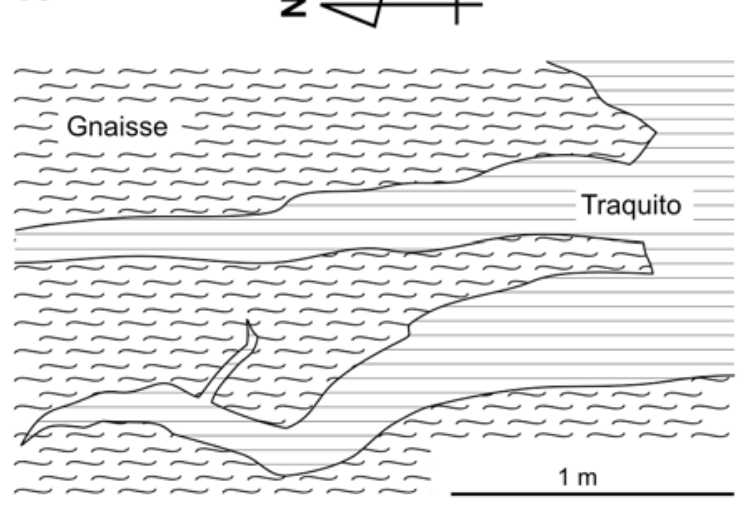

B

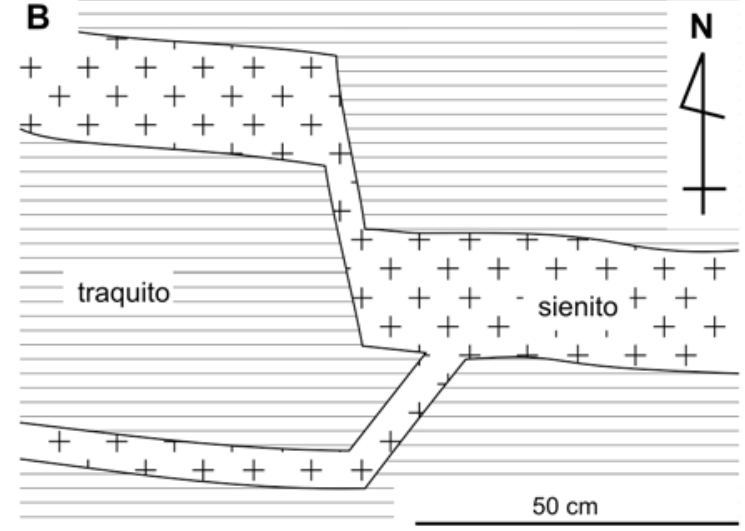

Figura 7 - llustração dos afloramentos intemperizados do traquito da primeira geração: A) intrudindo no embasamento metamórfico, estrada de acesso à serra do Vulcão (Loc. 3, Figura 1B); B) intrudido por álcali sienito, na serra do Vulcão (Loc. 5). 
As datações Ar-Ar em laser-spot para o traquito, álcali sienito e lamprófiro apresentaram idades próximas, em torno de $58 \pm 2 \mathrm{Ma}$ (Valente 2006, comunicação pessoal). Esse fato indica que não houve tempo suficiente para que o corpo sienítico fosse exposto na superfície por soerguimento para que fosse então recoberto por lava de traquito.

A parte do maciço Mendanha, inclusive o seu topo, expõe rochas sieníticas (Figura 8). Esses corpos plutônicos representam câmaras magmáticas da época do vulcanismo, que foram posicionadas em quilômetros de profundidade.

Os dados apresentados anteriormente levam a se concluir que o traquito não é constituinte de derrames de lava, mas de um corpo intrusivo subvulcânico.

\section{Feições peculiares do traquito}

Silveira et al. (2005) e Valente et al. (2005) apresentaram duas feições peculiares do traquito da primeira geração para justificar o modelo de lava: 1) disjun- ção colunar (Figura 9A); 2) crosta-depão (Figura 9B).

Disjunções colunares são formadas tanto em corpos extrusivos, como derrames de lava, quanto em corpos intrusivos subvulcânicos, como diques e sills. As disjunções colunares de lava e de depósitos de fluxos piroclásticos têm configuração vertical com diâmetro típico de 1 a 1,5 m (e.g. Roisenberg \& Viero, 2000). Por outro lado, as disjunções de corpos subvulcânicos têm diâmetro menor, de 30 a $60 \mathrm{~cm}$, apresentando notável desenvolvimento em comparação com lavas.

Disjunções de derrames de lava ocorrem com extensão quilométrica (Figura 10A). As colunas de diques são horizontais e ocorrem com extensão métrica (Figura 10B). Na ilha de Lutao, Taiwan, observa-se a transição de disjunções colunares horizontais de dique para aqueles verticais de lava (Figura 10C; Jiang \& Chen, 2004).

A disjunção colunar na região de Nova Iguaçu, apontada pelos trabalhos anteriores, tem $30 \mathrm{~cm}$ de diâmetro e foi observada em um bloco rolado de traquito na Loc. 12 (Figura 9A). O hexágono completo foi encontrado apenas nesse ponto, porém os incompletos estão espalhados em afloramentos isolados (Loc. 13, 14, Figura 1B). O diâmetro da coluna é pequeno demais para derrames de lava, porém é comum para corpos subvulcânicos. Essas observações sugerem que as disjunções colunares dessa área não são originadas de derrames de lava, mas de diques.

A estrutura de crosta-de-pão é observada em bombas vulcânicas de magmas félsicos. As gotas de magma contêm materiais voláteis, portanto ocorre expansão volumétrica por vesiculação. Quando a superfície das gotas é endurecida, ela se racha. Tais bombas são chamadas de bomba de crosta-de-pão (bread crust bomb). Fenômeno similar pode ocorrer raramente em clinkers de lavas viscosas (McPhie et al., 1993).

Valente et al. (2005) descreveram uma feição similar (Loc. 15, Figura 9B) e

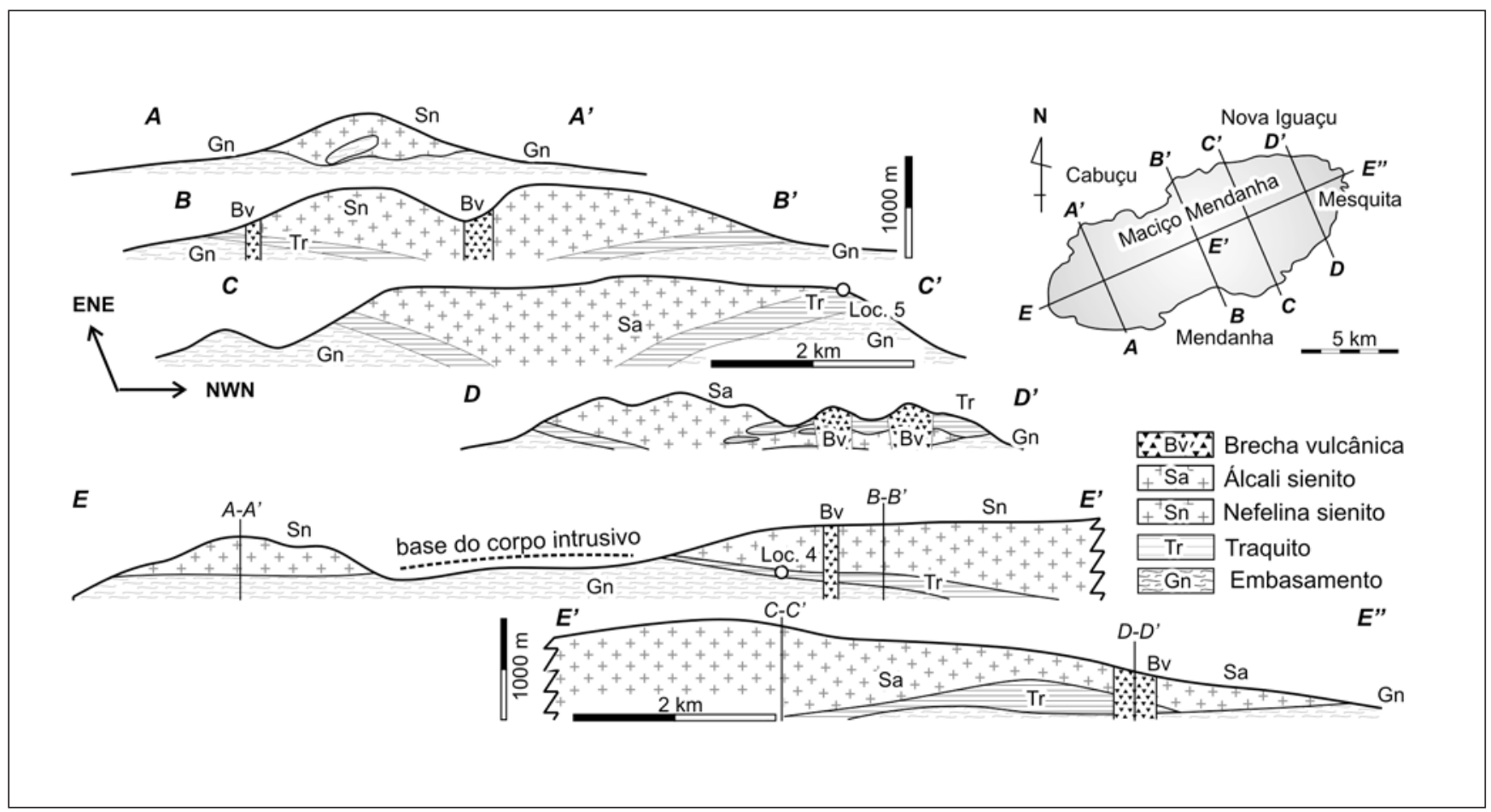

Figura 8 - Perfil geológico esquemático do maciço Mendanha, apresentando forma tridimensional do corpo intrusivo do traquito da primeira geração e sua relação com os corpos sieníticos. A escala vertical é exagerada 2,5 vezes seguindo o padrão da Figura 3 . 
a interpretaram como uma estrutura de clinker originada de lava traquítica. Entretanto, Klein et al (2001) e os trabalhos dos autores revelaram que nessa localidade expõe-se aglomerado com clastos arredondados de traquito. O perfil do clasto apresenta núcleo de traquito maciço, não vesicular (seta branca, Figura 9B), sem estrutura de crosta-de-pão na superfície original do clasto (seta amarela). Por outro lado, encontra-se uma feição intempérica chamada de pseudovesicular, resultante da lixiviação de cristais de minerais mais suceptíveis ao intemperismo (Motoki et al., 2007a). Portanto conclui-se que essa feição não justifica o modelo de derrame de lava.

\section{Conclusões}

As observações geológicas recentes na área de Nova Iguaçu e as análises vulcanológicas sobre possível existência de cratera, cone e derrames de lava apresentam os seguintes resultados:

1. A rocha constituinte do vale da suposta cratera vulcânica não é o aglomerado do conduto vulcânico, mas traquito maciço de primeira geração.

2. O depósito aluvionar presente no vale da suposta cratera tem espessura máxima de alguns metros e é composto de materiais regolíticos, não apresentando características de um depósito lacustre.

3. No vale da suposta cratera não se encontram os depósitos de tálus sugestivos de grande desmoronamento de paredes internas.

4. Não há morfologia e geologia de cone vulcânico.

5. Não ocorre a estratificação vulcânica de grande continuidade horizontal composta de spatter soldado.
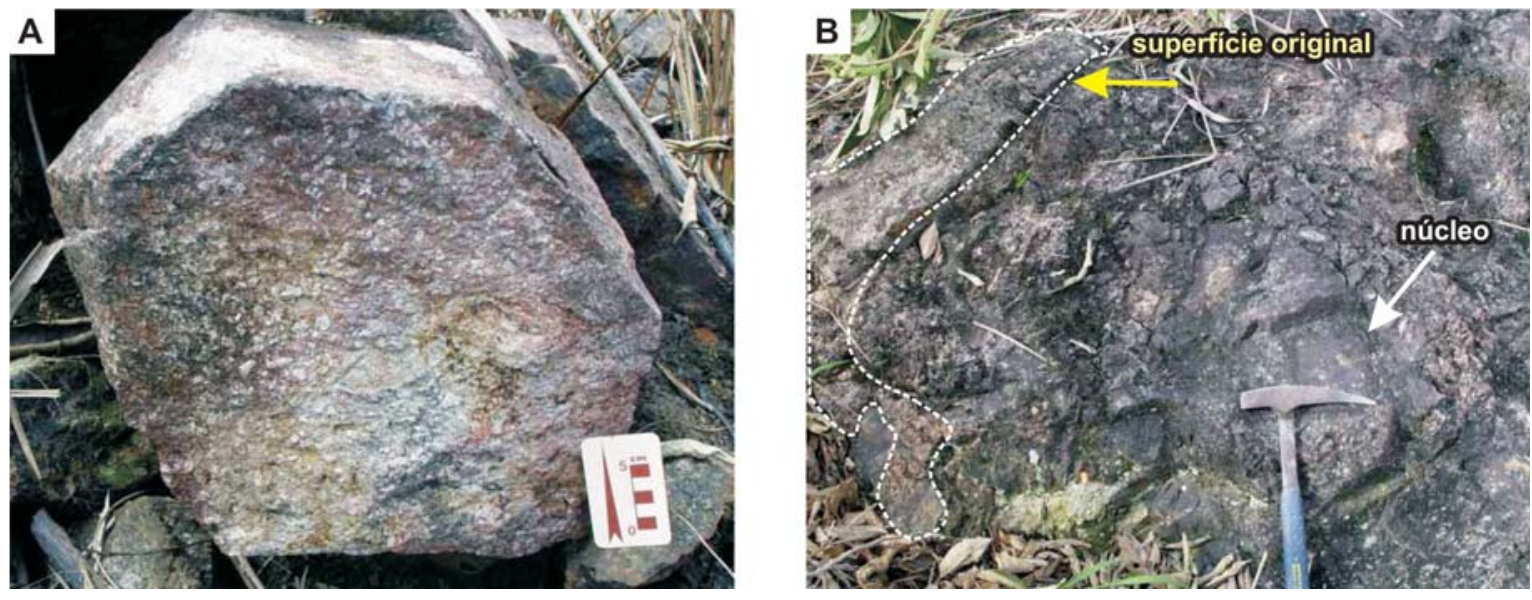

Figura 9 - Feições peculiares do traquito da primeira geração apontadas por Valente et al. (2005): A) disjunção colunar (Loc. 12, Figura 1; B) estrutura parecida com a crosta-de-pão (Loc. 15).

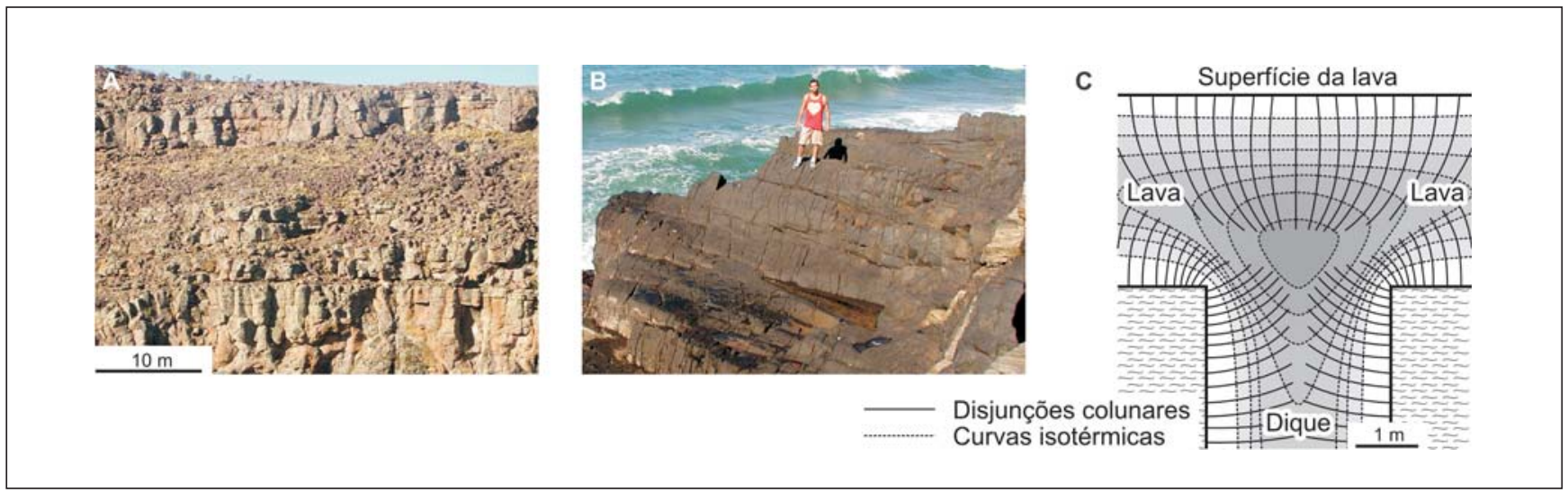

Figura 10 - Exemplos de disjunções colunares verticais e horizontais: A) colunas verticais de derrames de lava, Subida Tambelén, Meseda de Somuncura, Argentina; B) colunas horizontais de dique, Praia de Jeribá, Búzios, RJ.; C) transição de disjunções verticais em horizontais, ilha de Lutao, Pengfu, Taiwan, segundo Jiang e Chen (2004). 
6. As rochas traquíticas são divididas em duas gerações. A primeira geração é o traquito principal dessa região e forma um corpo intrusivo relativamente grande mais antigo do que o sienito. A segunda geração constitui diques mais novos do que o sienito.

7. O traquito da primeira geração não pode ser constituinte da lava que cobriu o substrato sienítico, devido a ser mais antigo do que o sienito.

8. O traquito da primeira geração é distribuído desde a cota de $40 \mathrm{~m}$ até $885 \mathrm{~m}$. Portanto não pode ser o derrame de lava emitida a partir da suposta cratera, localizado na cota 250 $\mathrm{m}$.

9. A feição de disjunção colunar é atribuída a disjunções horizontais de diques. A estrutura parecida à crosta-de-pão é considerada como de origem intempérica.

Klein e Vieira (1980) e Vieira e Klein (2004) consideraram que o efeito erosivo desta área desde o Cretáceo até o presente é nulo, o que conservou o cone e a cratera em estado intacto. Silveira et al. (2005) e Valente et al. (2005) interpretaram que a erosão é pouco intensa, o que preservou parcialmente o edifício vulcânico. Por outro lado, Motoki e Sichel (2006) e Motoki et al. (2006; 2007a; b) consideraram que o edifício vulcânico foi completamente eliminado pela profunda denudação regional e forte efeito de erosão tropical dessa região e os afloramentos atuais representam condutos e fissuras subvulcânicos de que ocorriam a quilômetros de profundidade. Os resultados do presente trabalho divergem das duas primeiras interpretações e corroboram a última. Desta forma, conforme a definição geológica do termo "vulcão" (MacDonald, 1972; Motoki \& Sichel, 2006), a estrutura geológica em discussão não pode ser chamada de "Vulcão de Nova Iguaçu".

\section{Agradecimentos}

Os autores são gratos à equipe do Projeto TAC, em especial ao Dr. Sérgio Valente da UFRJ, Dr. Edsom Mello da UFRJ, Nely Palermo da UERJ e Kátia Mansur do DRM e aos alunos colaboradores da etapa de campo Daniel Aderino, Ariadne Marra de Souza e Kenji Freire Motoki.

\section{Referências bibliográficas}

GERALDES, M.C., NETTO, A.M. Elaboração de placas do Geoparque do Vulcão de Nova Iguaçu-RJ: a utilização de linguagem popular para explicar a construção de um edifício vulcânico. In: CONGRESSO BRASILEIRO DE GEOLOGIA, 42. Anais... Araxá, SBG, CD, 1p, 2004.

GHIZI, A., MANSUR, K., VIEIRA, A.C. Geoparque do Vulcão de Nova Iguaçu. Homepage do Departamento de Recursos Minerais do Estado do Rio de Janeiro. http://www.drm.rj.gov.br/ item.asp?chave=109, 2004.

JIANG, W.S., CHEN, J.C. The topographic landscape of volcanic necks of the Coastal Range and Lutao, eastern Taiwan. Coll. and Res, Taipei, Academia de Ciências do Taiwan, v. 17, p. 82-92, 2004.
KLEIN, V.C., VIEIRA, A.C. Vulcões do Rio de Janeiro: breve geologia e perspectivas. Mineração Metalurgia, v. 419, p. 44-46, 1980.

KLEIN, V.C. O Vulcão Alcalino de Nova Iguaçu (Estado do Rio de Janeiro): controle estrutural e processo de erupção. Universidade Federal do Rio de Janeiro.1993. ( Tese de Doutorado) (inédito).

KLEIN, V.C., ÁVILA, C.A., DAYAN, H. Bombas “crosta de pão” (bread crust) nos depósitos piroclásticos do Vulcão de Nova Iguaçu, Rio de Janeiro. Boletim de Resumos do $7^{\circ}$ Simpósio de Geologia do Sudeste. Rio de Janeiro, SBG, CD, 2001. 1p.

KLEIN, V.C., VALENÇA, J.G., VIEIRA, A.C. Ignimbritos do Vulcão de Nova Iguaçu e da "Chaminé do Lamego", Rio de Janeiro. In: CONGRESSO BRASILEIRO DE GEOLOGIA, 33. Anais... Rio de Janeiro, SBG, p. 4346-4354, 1984.

MACDONALD, G.A. Volcanoes. Englewood Cliffs, Prentice-Hall, 1972. $510 \mathrm{p}$.

MCPHIE J., DOYLE M., ALLEN R. Volcanic Textures. A guide to the interpretation of textures in volcanic rocks. Centre for Ore Deposit and Exploration Studies, University of Tasmania, 1993. 198p.

MEDEIROS, F., RAGATKY, D. Geoparque de Nova Iguaçu - Falha do Poço das Cobras. Homepage do Departamento de Recursos Minerais do Estado do Rio de Janeiro, http://www.drm.rj.gov.br/ item.asp?chave=106, 2004.

MOTOKI, A., SICHEL, S.E. Avaliação de aspectos texturais e estruturais de corpos vulcânicos e subvulcânicos e sua relação com o ambiente de cristalização, com base em exemplos do Brasil, Argentina e Chile. REM - Revista Escola de Minas, v. 59, n. 1, p. 13-23, 2006.

MOTOKI, A., NETO, A.M., SICHEL, S.E., AIRES, J.R., SOARES, R., LOBATO, M. História de denudação regional e profundidade de posicionamento geológico das rochas vulcânicas de Nova Iguaçu, maciço Mendanha, RJ: constituintes de um vulcão ou corpos subvulcânicos? In: CONGRESSO BRASILEIRO DE GEOLOGIA, 43. Anais... Aracaju, SBG, p 136, 2006.

MOTOKI, A., SOARES, R., SICHEL, S.E., AIRES, J.R., LOBATO, M. Feições intempéricas em rochas alcalinas félsicas de Nova Iguaçu, RJ. REM - Revista Escola de Minas, v. 60, n. 3, p. 451458, 2007.

MOTOKI, A., SOARES, R., NETTO, A.M., SICHEL, E.S., AIRES, J.R., LOBATO, M. Forma de ocorrência geológica dos diques de rocha piroclástica no Vale do Rio Dona Eugênia, Parque Municipal de Nova Iguaçu, RJ. Geociências, Rio Claro, 2007b. (em submissão).

ROISENBERG, A., VIERO, A.P. O vulcanismo mesozóico da Bacia do Paraná no Rio Grande do Sul. In: HOLZ, M., DE ROS, L.F. (Ed.) Geologia do Rio Grande do Sul, Centro de Investigação do Gondwana, UFRGS, p. 355-374, 2000.

SILVEIRA, L.S., DUTRA, T., VALENTE, S.C., RAGATKY, D.C. Modelos eruptivos preliminares para o Complexo Vulcânico de Nova Iguaçu, RJ. In: SIMPÓSIO DE VULCANISMO E AMBIENTES ASSOCIADOS, 3. Anais...Cabo Frio, p. 333-337, 2005.

VALENTE, S.C., MELLO, E.F., PALERMO, N. Geologia de uma porção do complexo vulcânico de Nova Iguaçu limítrofe à área de lavra da pedreira Vigné, Nova Iguaçu, RJ. Relatório final. Nova Iguaçu: Ministério Público, 2005. 72p. (inédito)

VIEIRA, A.C., KLEIN, V.C. Vulcão de Nova Iguaçu, o vulcão brasileiro. CREA-RJ, 2004. 10p. (inédito)

VIEIRA, A.C. Pedreira destrói único vulcão intacto do país. Sérgio Torres. Folha de São Paulo, São Paulo, 3 de janeiro, 2005.

VIEIRA, A.C. Aventura, o vulcão carioca do esporte. Globo Hoje, Rede Globo, Rio de Janeiro, 21 de março, 2004.

Artigo recebido em 11/11/2006 e aprovado em 16/05/2007. 